\title{
La cuestión local en el Congreso Constituyente de 1917
}

\author{
Ernesto Azuela Bernal
}

El objetivo del presente ensayo es describir el debate en la Asamblea Constituyente de 1917 en torno a la cuestión local. Por "cuestión local" entenderemos a aquel grupo de temas que se refiere a la estructuración y organización de lo político en áreas distintas del Estado nacional, centralizado, pero inscritas en él. Esto es, lo local visto como un espacio donde operan mecanismos de integración y articulación políticos; donde se desarrollan formas sociales, institucionales y culturales de ejercicio político, que si bien pueden confluir en la conformación del Estado centralizado, existen por sí mismas.

Aunque es cierto que las regiones no son actores, si lo son sus habitantes. La manera de utilizar el espacio y sus diversas demarcaciones escapan a lo comunitario. El territorio tiene una historia, se constituye en un objeto de estudio por cuanto es el portador de las señales, de las huellas, de los rastros que nos permiten explicar y reconstruir las acciones de los hombres.

Con esto no se pretende aquí analizar lo local en términos de la geografía histórica. El territorio puede ser visto como objeto político. En la historia hay un proceso de establecimiento de relaciones de poder en el sistema espacial. La forma de organizar un territorio es uno de los puntos de partida para el análisis del Estado.

Podemos hablar entonces de una naturaleza espacial de los sistemas políticos. ${ }^{1}$

En este ensayo se define lo local como un área de exclusión de lo nacional. Así, la historia local es la historia de cada estado, de cada municipio, y también de los estados y municipios, pero no de la unidad en general. Es también la historia de las comunidades, ciudades, pueblos y rancherías.

Aquí lo local no está visto como espacio privilegiado para el análisis de fenómenos más generales que se ponen en el microscopio; lo local constituye un espacio, territorialmente diferenciado, con una especificidad que escapa a los polos de análisis posibles: la comunidad y lo nacional.

Interesa saber qué piensa la Asamblea Constituyente respecto a la participación de lo local en la construcción del Estado y qué prácticas reserva a cada ámbito. Esto es relevante pues una de las caracteristicas del Estado democrático está dada por la forma en que se articulan las estructuras locales. ${ }^{2}$

\footnotetext{
' José Abalos, "Introducción al estudio de los movimientos regionales", en Trimestre Económico, vol. LII, abril-junio, 1985, p. 381-383.

? Jordi Borja. "Descentralización: una cuestión de método", en Revista Mexicana de Sociología. IIS, UNAM, año XLVI, vol. XLVI, núm. 4, octubre-diciembre, 1984, p. 6.
} 
Así el desarrollo moderno de un Estado democrático supone un proceso constante de descentralización. De ahí que interese en qué medida los diputados constituyentes se propusieron la creación de un Estado altamente centralizado y de cómo pensaban la vida política local.

Para los propósitos de este trabajo, lo local ha sido definido en términos de exclusión y no como espacio demarcado; es decir que conforma su problemática lo relativo a lo local, lo estatal y lo municipal. Tratar como semejantes estos tres recortes espaciales se dirige a resaltar el área de exclusión.

En el marco de esta área de exclusión no nos interesan todos los temas, sino aquéllos que nos parecen fundamentales en la Constitución del 17 en materia agraria, laboral, educativa, y lo relativo a la libertad municipal.

Por lo tanto, nos parece importante situar la discusión de la Asamblea y con ese objeto, en una primera parte, esbozaremos algunos antecedentes, para pasar en seguida a describir la composición de la Asamblea. En una segunda parte, se caracterizarán las posiciones generales respecto a la cuestión local revisando algunos elementos interesantes del debate. Finalmente se abordará el debate sobre los artículos $3^{\circ}, 27^{\circ}, 123^{\circ}$ y $115^{\circ}$ constitucionales.

Indudablemente, los discursos teóricos y politicos que se ocupan de la cuestión local no siempre han estado referidos a los temas aquí delimitados. A veces se han orientado a la crítica del poder central y centralizado, otras a las propuestas de eficiencia descentralizadora y, también, a la defensa localista de los espacios políticos. Estos espacios han sido en ocasiones violentados en su forma de gobierno o en su división territorial y, además, ha sido en los espacios privilegiados donde se han expuesto las posturas de mayor relieve respecto a dicha cuestión.

Sin embargo, estos temas nos exceden pues no nos proponemos ni una discusión teórica alrededor de lo local, ni participar en el debate político. Es sólo un esfuerzo descriptivo que pretende ayudar a aclarar la situación de algunos aspectos de la cuestión local en la Asamblea Constituyente de 1917.

\section{Antecedentes}

Durante el Porfiriato, la vida política de los ayuntamientos estuvo regida por la alianza entre los hacendados y los jefes políticos. Desde la Colonia, los municipios habian perdido paulatinamente su autonomia hasta quedar subordinados a los jefes políticos en los términos de la Constitución de Cádiz. Su situación en el Porfiriato fue resultado de la continuación de esa tendencia por las políticas liberales. ${ }^{3}$ Ya entonces, los jefes políticos cumplian una función de

\footnotetext{
${ }^{3}$ Entre los intendentes, los corregidores y los prefectos o jefes políticos, podemos encontrar una línea de continuidad si analizamos las prerrogativas de que disfrutaban y especialmente sus atribuciones de control sobre la vida de los ayuntamientos. Esta es una tendencia a la subordinación política de los ayuntamientos. Véase Agustín Cué Cánovas, Historia social y económica de México (1521-1854), México, Trillas, 1969, p. 135-167. Respecto a los jefes políticos en las Cortes de Cádiz, véase Maria del Refugio González, "Debates sobre el régimen del municipio de México en el siglo XIX"; en Ruiz Massieu y Diego Valadez, Nuevo Derecho Constitucional Mexicano, México, Porrúa, 1983. p. 201-204. Respecto a la función
} 
mediación entre las instancias locales y nacionales cuyo elemento coercitivo fundamental eran los "rurales". 4

La Revolución mexicana subvirtió el orden político rompiendo los mecanismos de control y subordinación de los órdenes locales y estatales. Las fuerzas políticas que confluyen en la Revolución tienen una clara filiación local; así, por ejemplo, las reivindicaciones del ejército zapatista están referidas a las tierras y el gobierno de los pueblos, ${ }^{5}$ mientras que las fuerzas de los ejércitos del norte (villistas, orozquistas y carrancistas) se originan y desarrollan sobre la base de intereses locales, estatales y municipales. ${ }^{6}$ De aquí que no sea sorprendente que casi todos los manifiestos y planes de la Revolución hagan referencia a la cuestión municipal, ${ }^{7}$ que en el sentido de restitución de las tierras a los pueblos, devino elemento fundamental de la ideología de la Revolución. Fue vista como un problema de restitución de la tierra de los pueblos y así aparece en las leyes agrarias de Villa, de Carranza y de la Convención de Aguascalientes. $^{8}$

Finalmente, es necesario mencionar que en su campaña periodística en favor de una nueva Asamblea Constituyente, Palavicini propone: "Aspiramos ahora a una federación de los estados, para que mañana si es posible, lleguemos a una federación de municipios."9

\section{Composición de la Asamblea ${ }^{10}$}

El decreto de Carranza que convocaba a la realización del Congreso Constituyente fijaba las características que debian reunir los diputados, entre otras, tres condiciones fundamentales: 1) que fue-

del jefe político durante la República Liberal, veáse J. Mecham, "El jefe político en México", en Secuencia, Revista americana de ciencias sociales, Instituto de Investigaciones Dr. José María Luis Mora, núm. 4, enero-abril, 1986, p. 143-156.

+ Véase Dublán Lozano, Legislación Mexicana, México, imprenta y litografía Eduardo Dublán y Cía., 1887, vol. XVI. Juárez forma las fuerzas rurales para sofocar rebeliones militares y levantamientos de pueblos sin necesidad de usar al ejército.

5 Véase John Womack, Zapata y la Revolución mexicana, México, Siglo XXI, 1982, 12a. ed., p. 1-36. Las rebeliones de los pueblos fueron características de la segunda mitad del siglo XIX. Véase Leticia Reina, Las rebeliones campesinas en México 1819-1906, México, Siglo XXI, 1980, p. 437.

6 Véase Hèctor Aguilar Camin, Sonora. La frontera nómada, México, Siglo XXI, donde el origen y la articulación local de las fuerzas que componen al ejército constitucionalista se analiza como elemento central para la explicación de la Revolución mexicana.

7 Esto aparece en el programa del partido liberal, que propone la supresión de los jefes políticos y el fortalecimiento municipal. Arnaldo Córdova, La ideología de la Revolución mexicana. México, ERA, 1985, p. 417, 422; véase el Plan de Ayala, en lo que se refiere a la tierra y libertad de los pueblos, y las adiciones al Plan de Guadalupe respecto a la libertad municipal, p. 454; el Programa de Reformas de la Convención en su artículo 32, p. 484. El Plan de la Empacadora en sus arts. 28 y 29 en La Rerolución mexicana. textos de su historia, Mexico, Instituto de Investigaciones Dr. José Maria Luis Mora/ Dirección General de Publicaciones y Medios, SEP. t. III, p. 146.

${ }^{*}$ Véase Arnaldo Córdova, op. cit., en el apéndice que da cuenta de estos documentos: véase también. Pastor Rouaix, Génesis de los articulos 17 y 123 de la Conslitución Política de 1917, México, PRI, 1985, caps. I, II y apéndices.

${ }^{9}$ Félix F. Palavicini, Un ntıevo Congreso Constituyente, México, Imprenta de la Secretaría de Instrucción Pública y Bellas Artes, 1915, p. 62.

${ }^{10}$ Para esta parte se utilizó el Diario de Debates del Congreso Constituyente, México, Comisión Nacional para la celebración del sesquicentenario de la procla- 
ran ciudadanos mexicanos, 2) que no hubieran servido a los gobiernos o a las fuerzas anticarrancistas y 3) que no tuvieran mando militar en el momento de las elecciones en la zona donde fueran elegidos. La Asamblea aplicó discrecionalmente estas reglas en la calificación de credenciales. ${ }^{11}$

Podemos afirmar en general, que la forma de la convocatoria generó una fuerte representación local cuya base fueron los viejos clubes maderistas, los caciques regionales y las clientelas políticas locales de ciertos grupos de interés. ${ }^{12}$ Además, las formas reales del proceso electoral dieron lugar a una representación de grupos políticos, o más bien, de personajes políticos de influencia nacional. ${ }^{13}$ Por último, hay una representación de grupos y caudillos revolucionarios de orden regional particularmente relevante en Sonora y San Luis Potosí. ${ }^{\circledR}$

Las pugnas entre estos grupos respecto a la calificación de credenciales lleva la discusión a un interesante ajuste de cuentas con la historia de la Revolución, cuyos elementos ideológicos más importantes aparecen ya fijados en el debate. ${ }^{15}$

Dentro de la Cámara las representaciones políticas y regionales terminan por conformar tres grupos: el grupo de la legislatura maderista y algunos otros personajes ligados a Carranza; ${ }^{16}$ el grupo llamado radical o "jacobino" ligado a los jefes revolucionarios, especialmente al grupo Sonora y otros militares, y la mayoría del Congreso en donde los intereses locales y regionales tenían un peso considerable. ${ }^{17}$

La importancia del voto regional y local, así como el de las representaciones de grupos o caudillos revolucionarios no se tradujo en una división del Congreso y menos aún en fracciones parlamentarias con tesis programáticas. Lo que sí encontramos es una posición más o menos critica de ciertas fracciones de la Asamblea al proyecto carrancista. ${ }^{18}$

\section{Posiciones generales respecto a la cuestión local}

El Congreso se mostró siempre muy atento en cuanto a mantener y fortalecer el régimen federal desde un punto de vista ideoló-

mación de la Independencia y el cincuentenario de la Revolución mexicana, 1960 , 2 t., 4 vols., 1104 y 1283 p., en adelante citado como D.D. Con.

11 Véase D.D. Con., t. I, vol. II, p. 47-560. Es curiosa la redacción del punto 1 que permitió que hubiera un cubano nacionalizado en la Cámara: el diputado José Marti.

12 Véase Charles C. Cumberland, La Revolución mexicana; los años constitucionalistas, México, FCE, 1975, p. 301-308, donde afirma la adversidad de la composición de la Asamblea.

${ }_{13}$ Ver D.D. Con., t. I vol. I, p. $47-560$ y passim. Constantemente se hace referencia a los padrinos políticos de los diputados y aun éstos hacen profesión de fe. Véase también Cumberland, op. cit., que destaca el caso de Jesús Acuña, secretario de Gobernación durante el proceso electoral.

14 Ibid.

is D.D. Con., loc. cit. Es interesante la calificación de I. Martínez, donde se habla del zapatismo. También la del bloque renovador donde se revisa la historia de la revolución maderista. Sobre la división ideológica, véase los discursos de Rojas en D. D. Con., t. I. vol. II y de Martínez Escobar, D. D. Con., t. II. vol. I; véase tambiên Rouaix, op. cit., cap. III.

${ }^{16}$ Loc. cit

17 Ibid. En Cumberland, op. cit., se afirma la división en este sentido.

18 Véase el discurso de Rojas después del debate del articulo $3^{\circ}$ en loc. cit. 
gico y práctico. Ideológico en tanto que establece una conceptualización de lo que es el Estado mexicano fijando las fórmulas con que debe ser entendida su estructuración. Así, también establece esferas de práctica política exclusivas para lo local y lo municipal, además de que abre su participación en áreas antes reservadas a lo federal.

Desde el principio del debate de la Asamblea Constituyente se cuidaron las formas ideológicas. Un ejemplo de ello fue cuando la Comisión I propuso en el preámbulo de la Constitución que el nombre del país fuera República Mexicana y no Estados Unidos Mexicanos. Se señaló la connotación centralista de la primera denominación y finalmente fue derrotada la propuesta. ${ }^{15}$ De ahí en adelante, el cuidado formal respecto a los asuntos locales y municipales permearia el debate constitucional.

Así, el modelo constitucional respeta la fórmula que establece que las facultades de los poderes federales estén claramente determinadas y que todas las áreas que no están explícitamente reservadas se atribuyan a las entidades federativas. En la lógica constitucional, aparece el poder federal como constituido y los poderes estatales como constituyentes, por cuanto ceden parte de sus atribuciones al primero. ${ }^{20}$

Un argumento reiterado en el conjunto del debate de la Asamblea fue la necesaria descentralización del ejercicio del poder y el reconocimiento de la capacidad de los estados y regiones para participar en la solución de los problemas nacionales. ${ }^{21}$ Por ejemplo, quedó claramente definida la intención descentralizadora cuando se planteó la cuestión penitenciaria. El proyecto de Carranza pretendía el establecimiento de un sistema federal de colonias penitenciarias sustentado en la teoría de la rehabilitación social. Frente al proyecto se afirmó repetidamente la capacidad de los estados para ejercer esta función y se criticó fuertemente la pretensión centralizadora. Aquí, los argumentos de la descentralización dominaron el debate. ${ }^{2}$

Otra postura general apareció en relación a las atribuciones de la Suprema Corte de Justicia respecto al derecho de amparo, para impedir que en el futuro se volviera a suscitar el problema del amparo de origen sustentado en el artículo 16 constitucional. ${ }^{23}$

En materia económica, y al plantearse la discusión del artículo 28 constitucional -sobre los monopolios-, la diputación de Yucatán propuso que no se consideraran monopolios a las sociedades de productores que vendieran al extranjero aquellos productos nacionales que fueran la principal fuente de riqueza de una región. Esta propuesta fue duramente debatida -especialmente por los grupos que representaban intereses más nacionales- y sin embargo

${ }^{19}$ D.D. Con., t. I, vol. II, p. 590-615.

${ }^{20}$ Tena Ramirez, Leyes fundamentales de México 1808-1857, México, Porrúa, 1957 , p. 827 , art. 124 , constitucional.

21 Véase en especial los discursos de Calderón y Medina en el debate del artículo 18, D.D. Con., t. II, vol. I.

22 Véase la discusión del artículo 18 , en especial el debate del 3 de enero, $D . D$. Con., t. II, vol. 1, p. 44-68.

${ }^{23}$ Respecto al amparo de origen, véase Rabasa, El juicio constitucional; origen, teoria y extensión. México, Líbrería de la Vda. de Čh. Bouret, 1919, 348 p. En la Asamblea fue H. Medina quien planteó la cuestión. D.D. Con., t. I, vol. II, p. 34-37. 
se impuso la lógica local y la propuesta fue aceptada por la Asamblea. Se estableció así un privilegio regional a ciertos productores para monopolizar sus productos de exportación.

Aunque este privilegio no se utilizara significativamente, es importante señalar la intención de la mayoría del Congreso. ${ }^{24}$

La cuestión militar fue un asunto fundamental que la Asamblea no pudo tratar por falta de tiempo, o porque no lo quiso enfrentar. La Comisión II presentó un dictamen y algunos diputados (Jara, Mújica y otros) presentaron una iniciativa. En las dos propuestas se buscaba establecer las bases orgánicas para el funcionamiento del ejército, la armada y la guardia nacional. ${ }^{25}$

En los dos proyectos, la guardia nacional quedó establecida constitucionalmente, pues según el artículo 89 de la constitución vigente, el presidente tiene atribuciones para movilizarla. ${ }^{26} \mathrm{La}$ guardia debía estar formada por milicias municipales con la función de resguardar el orden público en la localidad. Su organización correspondía al ayuntamiento y su movilización recaería sobre el gobernador, previa autorización de la legislatura. Las milicias se integrarían con ciudadanos voluntarios y se reunirian por convocatoria. Por lo tanto no eran fijas, ni sus integrantes tenían retribución.

La importancia de esta institución fue reiterada en distintas etapas de la Asamblea. En ningún momento se puso en duda el necesario carácter local de la guardia nacional. Sin embargo, el penúltimo día la Asamblea votó una moción suspensiva que impidió que se discutiera y aprobara el dictamen, quedando de acuerdo en que el primer Congreso debería hacer la correspondiente adición a la Constitución. La cuestión militar fue la única sobre la cual la Asamblea se negó a legislar por falta de elementos de juicio suficientes. $^{27}$

Durante los tres meses que estuvo reunida la Asamblea, se recibieron peticiones de casi todo el país para reformar los límites y aun para cambiar la división territorial del país. Además, distintas diputaciones estatales promovieron iniciativas en este sentido que fueron rechazadas por las respectivas diputaciones de las entidades afectadas.

La Constitución del 57 incluyó varias modificaciones en la división territorial; de ahí, tal vez, la multitud de peticiones en este sentido que aparecen resumidas en el dictamen del artículo $44 .^{28}$

Fue tal la cantidad de iniciativas y tan violento el debate que no hubo lugar a ningún tipo de negociación, por lo que la Asamblea decidió no votar ningún cambio. Es necesario anotar que la primera iniciativa de cambios en la división territorial apareció en el proyecto de Carranza que pretendía ampliar los límites del Distrito Federal con fines políticos y militares.

24 Especialmente cuando se vio el modelo monopólico henequenero como generalizable para otros productos. D.D. Con., t. II, vol. I, p. 534-548. Es interesante anotar que los llamados "jacobinos" compartieron posiciones con los "conservadores" contra los privilegios regionales y fueron derrotados. Véase las participaciones de Palavicini y Von Wersen, que formaban parte de estos grupos.

is D.D. Con., t. II, vol. II, p. 975.

26 Articulo 89, fracción Vil de la Constitución de los Estados Unidos Mexicanos.

${ }_{27}$ Véase D.D. Con., t. II, vol. II, p. $1137-1141$.

28 D.D. Con., t. II, vol. II, p. 998-999 y passim. 
El proyecto de Carranza proponía unificar el valle de México bajo la jurisdicción del Distrito Federal, para componer una entidad política, autosuficiente económicamente y militarmente "inexpugnable" dadas las caracteristicas del relieve. ${ }^{29}$

Es importante señalar que la Asamblea discutió si el municipio debía ser soberano al igual que los estados. Esta discusión revela el interés en el Constituyente por la libertad municipal y lo poco sustantivo de la teoría de la soberania en la tradición constitucional mexicana. ${ }^{30}$ La cuestión de la soberanía está en referencia a si el municipio tiene poder propio atribuido por el pueblo, o bien ejerce administrativamente funciones delegadas por otro poder. El asunto no se aclaró debido a la pobreza teórica con que se discutió.

Por último, es importante decir que la Constituyente estableció que los congresos estatales tuvieran un mínimo de 15 miembros. En el debate es claro que la intención es la de conformar legislaturas lo más plurales posibles, lo que a los ojos de la Asamblea implicaba que al menos hubiera 15 representantes en la Cámara. ${ }^{31}$

\section{La cuestión local en los temas centrales de la Asamblea Constituyente}

Consideramos como temas centrales del Congreso Constituyente los relativos a la educación, al trabajo, a la reforma agraria y, de acuerdo con el objetivo del presente ensayo, a la libertad municipal.

El debate sobre la educación marcó el punto de inflexión en la historia de la Asamblea, que a partir de ese momento realizó una crítica más radical del proyecto constitucional de Carranza y se propuso incorporar explícitamente a la Constitución los objetivos de la Revolución mexicana. En ese momento la Constitución pasó a ser la portadora del programa de reivindicaciones de la Revolución y por tanto, la expresión del proyecto de nación de la fracción triunfadora en la lucha armada. ${ }^{32}$

La responsabilidad de los establecimientos educativos, tal como se desprende del debate del Constituyente, cae en la esfera municipal y es de su responsabilidad el fomento y desarrollo de esta actividad primordial, en términos tanto políticos como ideológicos. ${ }^{33}$

Asimismo, la legislación en materia educativa se entiende en el contexto de la esfera local y en ningún momento aparece la intención de federalizarla. ${ }^{34}$ Por esta razón, la Constitución incluía en sus artículos transitorios la supresión de la Secretaría de Instrucción Pública y Bellas Artes.

29 Véase loc. cit. y el discurso inaugural.

${ }^{30}$ Este asunto se tocó al discutir la forma de gobierno. Véase D.D. Con., t. I, vol. II, p. 964-968.

3f Véase Discusión del art. 115 constitucional en especial el discurso de Mújica, D.D. Con., t. II, vol. II, p. 914-915.

32 Ibid., t. I, vol. II, p. 638-774.

33 Este fue el marco en que la Asamblea discutió siempre el problema, véase loc. cit.

34 Unicamente Palavicini propuso la formulación de un sistema que diera unidad a la educación en el país. Pero sus proposiciones no fueron recogidas en el texto constitucional. D.D. Con., t. II, vol. II, p. 624-634.

35 Véase artículo 14 transitorio en Tena, op. cit., p. 880. 
Concebir la educación en la esfera de la legislación local nos remite a las fórmulas descentralizadas con que se manejó esta materia en el periodo liberal y también en la época de la Colonia.

En el periodo colonial la educación superior se otorgaba en concesión por mercedes reales y estaba fomentada por patronatos y reglamentada por ordenanzas especiales; para cada institución se seguía una politica específica. La educación elemental no estaba reglamentada. En el periodo liberal, la educación era de jurisdicción estatal; la Ley de 2 de diciembre de 1867 establecía su condición secular y científica, sin estorbar las facultades locales. ${ }^{36}$

En lo que se refiere a la cuestión agraria, el carácter local con que fue concebido el artículo 27 constitucional es muy claro, pues establece fórmulas que permiten la adaptación normativa a las diferentes condiciones y, especialmente, porque retoman las instituciones del derecho público español, no sólo en lo que se refiere a. la propiedad original de la tierra, sino también a la propiedad de los pueblos, vistos como corporaciones sujetas a dotación y ampliación de los fundos y como sujetos de restitución. Se establece, en consonancia con las ordenanzas reales, el límite de dominio que impide a los pueblos enajenar la propiedad. ${ }^{37}$

Estos ordenamientos que podría pensarse que están dirigidos a la rehabilitación de la vida económica de los ayuntamientos de los pueblos, no reconstituyen esa entidad liquidada por el liberalismo, sino que establecen las reglas para el nacimiento y desarrollo de una nueva forma de propiedad ligada a prácticas políticas novedosas, fincando una nueva base de articulación de los campesinos a la vida política en las arenas locales y nacionales.

De ahí que los campesinos participen en la vida política con organizaciones permanentes propias. Sin fundamento político institucional su participación se organizaría todavía o por la vía clientelista, o desvinculada del Estado.

Está en la intención del Constituyente que estas nuevas bases de organización se estructuren a escala municipal, estatal y nacional, distribuyendo las atribuciones en la materia. Pero fundamentalmente corresponde a las legislaturas locales expedir leyes para llevar a cabo el fraccionamiento de las grandes propiedades y la dotación correspondiente. ${ }^{38}$ Es muy ilustrativo el procedimiento que establece el artículo 27 en su versión original, pues la participación de los poderes federales se limita a resolver concesiones en materia de subsuelo, facultar a los congresos locales para emitir bonos de deuda agraria y controlar la propiedad de la Iglesia. ${ }^{39} \mathrm{El}$ resto de las atribuciones son de jurisdicción estatal, dando espacio a la participación municipal en lo que se refiere a la intervención de la autoridad administrativa para ocupar, administrar, rematar o vender las tierras objeto de expropiación. La autoridad adminis-

${ }^{36}$ Cué Cánovas, op. cit.

37 Véase Andrés Molina Enríquez, La revolución agraria en México; 1910-1920, México. Porrúa. UNAM (IIJ), 1986.

${ }_{38}$ Véase el discurso de Bojórquez, D.D. Con., t. II, vol. II, p. 1085 y el de Medina. El dictamen de la comisión es claro en el sentido de la distribución de atribuciones.

${ }^{39}$ A pesar de que toda la materia religiosa se federalizó, las atribuciones mencionadas quedaron en la esfera estatal. Véase art. 130, Tena, op. cit. p. 875. 
trativa más simple es la municipal, así quedó entendido para la Asamblea a partir del debate de los articulos 18 y 19 . $^{40}$

La manera en que se realizó la reforma agraria en cada entidad respondió a sus condiciones políticas, y la velocidad e importancia del reparto agrario deben ser vistos en ese contexto. ${ }^{41}$ Por ello resulta inexacto afirmar que durante el periodo inmediato a la promulgación de la Constitución, el Ejecutivo Federal fue moroso para realizar la reforma agraria. El presidente de la República no tenía atribuciones más que en la zona de jurisdicción federal, especialmente importante en las áreas donde los terrenos nacionales eran de consideración, como en la región norte del país donde los nacionaleros demandaban la tenencia de la tierra. ${ }^{42}$ En casos particulares, el presidente pudo hacer uso de la Ley del 5 de febrero de 1915 para realizar repartos en zonas de jurisdicción estatal. ${ }^{43}$

El apartado laboral constituyó uno de los problemas fundamentales de la Asamblea Constituyente. La votación del artículo $5^{\circ}$ quedó bloqueada cuando los distintos proyectos que presentó la comisión le parecieron insuficientes a la Asamblea. La salida apareció con la conformación de la comisión oficiosa que patrocinó Pastor Rouaix. $^{44}$

Sin embargo, es importante señalar que José Natividad Macias, por instrucciones de Carranza, presentó a la Asamblea el proyecto de ley de trabajo para el distrito y territorios federales, que por haberse federalizado la materia, no se pudo expedir. Macias hace una exposición de los elementos centrales que más tarde conformarian el artículo $123 .^{45}$ Estos dos datos son significativos en la historia del Congreso. La Asamblea establece la jurisdicción local de la materia de trabajo y recoge los planteamientos integros de la Comisión Rouaix. ${ }^{46}$

Las atribuciones en materia de trabajo quedan distribuidas entre los niveles de gobierno. Al municipio le corresponde la fijación de los salarios mínimos a través de una comisión adhoc, ${ }^{47}$ y el reparto de utilidades y la supervisión de los contratos entre mexicanos y extranjeros. ${ }^{48}$ Corresponde a los congresos locales legislar en esta materia, y asimismo, establecer los tribunales de conciliación y arbitraje.

Vemos así que la arena política de los conflictos laborales queda establecida en el espacio local concebido como el foco de la vida

${ }^{40}$ Vèase D.D. Con., t. I, vol. II, p. 894-913.

41 Las distintas condiciones en las fuerzas políticas locales empujaron o detuvieron el reparto. El caso de Michoacán es ejemplar si confrontamos las acciones agrarias de Cárdenas con las de su sucesor.

${ }_{42}$ Los nacionaleros, posesionarios de terrenos nacionales, fueron parte importante de los ejércitos de Pascual Orozco y Francisco Villa. Véase el Plan de la Empacadora que tiene su parte esencial en la reivindicación de los derechos de ocupación de los nacionaleros.

${ }^{4,3}$ La ley siguió vigente de acuerdo al texto constitucional, lo que posibilitó las acciones del ejecutivo federal en algunos casos.

${ }_{44}$ Véase la participación de Macías, D.D. Con., T. I, vol. II, p. 968-989, 10011021 y 1023-1058: véase también Rouaix, op cit., cap. III.

45 Véase Macias, loc. cit.

46 A excepción del reparto de utilidades y el derecho a la vivienda que por iniciativa de Mújica se incluyó en el dictamen y prevaleció.

${ }^{47}$ D.D. Con., t. II, vol. II, p. 844 y ss.

48 Ibid.

49 Véase D.D. Con., t. II, vol. II, p. 860 y passim. 
política obrera en el proyecto constitucional. Esto, frente a las tendencias sindicales de formar organizaciones nacionales, pareceria ilógico, sin embargo respondía a la presencia que tradicionalmente habían tenido los trabajadores artesanos en la vida política local, especialmente en los ayuntamientos urbanos. Los artesanos constituyeron una importante clientela política local en el siglo XIX. ${ }^{50}$

En lo que se refiere al municipio, su organización quedó establecida en el artículo 115. La Asamblea Constituyente instituyó dos principios: primero, que la base de la división territorial de los estados fuera el municipio sin intermediar ninguna autoridad entre los poderes estatales y el ayuntamiento y, segundo, que el municipio era libre, para lo cual se le reconocía personalidad jurídica y capacidad para administrar su hacienda. ${ }^{51}$ Esto último bajo supervisión de la legislatura local.

La cuestión de la hacienda municipal y los recursos que la forman han sido el tema central que ha guiado la discusión sobre el municipio desde entonces. El voto particular de Jara y Medina establece los elementos centrales de esta añeja discusión al plantear que la libertad política sin capacidad económica no existe. Este argumento se ha venido repitiendo desde entonces. ${ }^{52}$

El debate de la Asamblea se centró en las cuestiones fiscales buscando una fórmula que permitiera que el gobierno estatal y el municipal tuvieran una fuente segura y autónoma de recursos. ${ }^{53}$ Sin embargo, no se pudo establecer tal fórmula, pues la Asamblea veía que se lesionaban las atribuciones estatales al intentar fijar cualquier modalidad de régimen fiscal. Quedó por tanto una redacción de compromiso que dejó a los legisladores locales determinar los recursos del municipio, estipulándose que debían ser suficientes. Esta fórmula contenía los mismos elementos que la instituida en la Constitución de Cádiz que establecía la supervisión y la aprobación de la diputación provincial sobre los recursos además del control del ejecutivo local (desaparición de poderes municipales) y así también la organización interna libre.

El debate alrededor del artículo 115 es interesante pues delimita los aspectos que la Asamblea atribuye a los poderes estatales y al gobierno municipal, donde no cabe ninguna injerencia federal. ${ }^{55}$

Mas es un hecho que en el texto constitucional, lo local y lo municipal quedaron establecidos como áreas de estructuración de lo político, arenas de disputa y negociación a partir de las que, de acuerdo con las características regionales, se conformaria la hege-

\footnotetext{
so Véase Juan Felipe Leal, Historia del movimiento obrero. Del estado liberal a los inicios de la dictadura, México, Siglo XXI, 1980, 2a. parte; véase Manuel Carrera Stampa. Los gremiós en México. La organización gremial de Nueva España 15211861, México, EDIAPSA, 1954, p. 155-156 y passim.

51 Véase el dictamen y el voto particular de Jara y Medina en D. D. Con., t. II, vol. II. p. 870 y ss.

si Véase Ruiz Massieu, op. cit, donde al tratar la reforma al artículo 155 el conjunto de sus textos trata asi el problema municipal, en concordancia con la exposición de motivos de la iniciativa presidencial para la reforma del 115 , que es consultable en el diario de debates correspondiente.

${ }^{53}$ El planteamiento del problema fiscal en D.D. Con., t. II, vol. II, p. 881-909 y 1064-1080.

${ }_{54}$ Véase Refugio González, op. cit

ss A la Federación no le corresponden atribuciones que toquen lo político municipal. la Asamblea cuidó de no romper el orden de conexión federal-estatal-municipal, D. D. Con., t. II. p. 898 y 1064.
} 
monía del nuevo Estado nacional que nace con la Revolución mexicana. ${ }^{56}$

\section{Conclusión}

La Asamblea Constituyente al organizar el mundo politico local no intentó inventar instituciones novedosas. Las fórmulas que aprobó tienen sus raíces en la historia aunque en el contexto de la Constitución de 1917 adquieren un nuevo significado. Esto corresponde a una lógica que busca revertir y modificar las estructuras de dominación èstablecidas por el antiguo régimen. La Asamblea reconoció en el orden local una de las vertientes donde se articulaba esa dominación.

Las reformas tienen un doble sentido: restituir los derechos y libertades perdidas y organizar la vida política local de una forma novedosa, articulada con una idea de lo que debía ser el régimen politico de México.

Las reformas a la Constitución que fueron concentrando las atribuciones en la federación impidieron el desarrollo del modelo previsto por los constituyentes.

En este sentido, una primera conclusión nos lleva a reconocer una propuesta política que buscaba organizar la vida institucional del país a partir del desarrollo de las fuerzas políticas locales, pues no consideramos que las decisiones reseñadas fueran ingenuas o vacias. Es evidente una intención política y podriamos afirmar que fue un proyecto derrotado, pero nunca un desliz o una ingenuidad.

En segundo lugar podemos afirmar que las distintas reformas que han modificado las atribuciones estatales y municipales desde 1917 a la fecha, han tenido el carácter y la trascendencia de verdaderas reformas políticas, en tanto que han modificado los espacios de desarrollo, de confrontación y de negociación de las fuerzas sociales limitando la pluralidad de la vida pública, estructurándola de una cierta manera. Con las reformas constitucionales se generó un proceso histórico de traslado de funciones y atribuciones que marcó las características de centralización de nuestro actual régimen político.

so La autonomia de este espacio fue desarticulado con las reformas constitucionales siguientes, especialmente de Calles y Cárdenas. Véase Tena, op. cit., p. 933 y 936. asi como p. 881-932 donde se detallan las distintas reformas a la Constitución. 